\title{
Surgical management of middle cerebral artery aneurysms
}

\author{
Mugurel Radoi ${ }^{1,2}$, Florin Stefanescu ${ }^{1,2}$, Ram Vakilnejad ${ }^{2}$ \\ 1 Faculty of General Medicine, "Carol Davila" University of Medicine and \\ Pharmacy, Bucharest, ROMANIA \\ 2 Neurosurgical Department of the National Institute of Neurology \\ and Neurovascular Diseases, Bucharest, RomanIA
}

\begin{abstract}
Background. The middle cerebral artery (MCA) harbors approximately $14 \%$ to $30 \%$ of all ruptured cerebral aneurysms. They can occur at multiple sites throughout the course of the middle cerebral artery, but most often are found at the bifurcation of the first segment (M1).

Methods. A retrospective review of 116 consecutive patients with an MCA aneurysm treated by surgical clipping, by two senior neurosurgeons, was performed. The data of all our consecutive patients were searched to obtain patient characteristics, details of the aneurysm size and orientation, treatment details, complications and follow up. At admission, the clinical condition of all patients was classified according to the Hunt and Hess scale. Clinical outcome was graded according to the modified Rankin scale. The follow-up period varied widely from 2 to 72 months (mean 30 months).

Results. Surgical clipping was performed for 113 ruptured MCA aneurysms; only in 3 cases the aneurysm was unruptured. Fourteen patients presented with significant hematoma which required the evacuation of the clot. Post-operative control angiography was performed in 32 patients (27.5\%), from which we reported a full occlusion of the aneurysm in 32 patients (93.75\%). Perioperative mortality was $5.2 \%$ (6 patients), due to neurological (4 patients) or systemic causes (2 patients). The outcome was graded mRankin $0-2$ in $72.5 \%$ of the cases (84 patients) at the end of the first postoperative months, and $78.5 \%$ (91 patients) at six months follow-up. The most important improvement was recorded for patients graded mRankin 1-2 at the first month follow-up. All 3 patients with a surgically treated asymptomatic MCA aneurysm had an excellent outcome (mRS 0) at both follow-up, 1 months and respectively 6 months.
\end{abstract}

Conclusions. For experienced neurovascular team, MCA aneurysms currently make microsurgical treatment the preferred treatment modality for most MCA aneurysms.

\section{INTRODUCTION}

The middle cerebral artery (MCA) originates at the internal carotid artery (ICA) bifurcation and courses laterally within the sylvian cistern. MCA aneurysms are common, representing approximately $14 \%$ to $20 \%$ of all intracranial aneurysms $(13,24)$. They can occur at multiple sites throughout the course of the middle cerebral artery, but most often are found at the bifurcation of the first segment (M1) and projects laterally

\section{Keywords \\ MCA aneurysm, \\ surgical clipping, \\ endovascular treatment, \\ postoperative results}

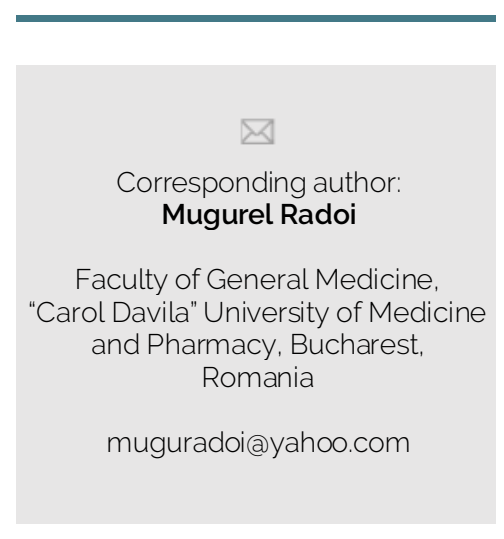

Copyright and usage. This is an Open Access article, distributed under the terms of the Creative Commons Attribution Non-Commercial No Derivatives License (https://creativecommons org/licenses/by-nc-nd/4.0/) which permits noncommercial re-use, distribution, and reproduction in any medium, provided the original work is unaltered and is properly cited.

The written permission of the Romanian Society of Neurosurgery must be obtained for commercial re-use or in order to create a derivative work.

ISSN online 2344-4959

(C) Romanian Society of Neurosurgery

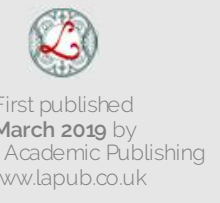


in the plane of the M1 segment (31). Because they project into the adjacent brain parenchyma, MCA ruptured aneurysms are more likely to present with intraparenchymal rather than subarachnoid haemorrhages. Thus, intracerebral haemorrhage rate is $43 \%$ versus $11 \%$ for aneurysms in other locations $(13,24)$.

\section{Methods}

A retrospective review of our neurovascular database was performed for patient diagnosed and surgically treated for MCA aneurysm in the period from January 2012 until May 2018, by two senior neurosurgeons. In this period, 116 consecutive patients with an MCA aneurysm were treated by surgical clipping, from a total of 384 patients operated for cerebral anterior circulation aneurysms. From this series of 116 patients, 26 patients harboured multiple intracranial aneurysms and at least one MCA aneurysm. Of our patients with multiple intracranial aneurysms, 12 had bilateral MCA aneurysms (mirror aneurysms).

TABLE 1 - Distribution of carotid system aneurysms in a series of 116 patients

\begin{tabular}{|l|l|}
\hline \multicolumn{2}{|c|}{ Distribution of carotid system aneurysms } \\
\hline Aneurysm location & Number of patients \\
\hline Anterior communicating artery aneurysm & $168(44 \%)$ \\
\hline Posterior communicating artery aneurysm & $75(19.5 \%)$ \\
\hline Right medial cerebral artery aneurysm & $65(17 \%)$ \\
\hline Left medial cerebral artery aneurysm & $51(13 \%)$ \\
\hline Anterior cerebral artery aneurysm & $4(1 \%)$ \\
\hline Internal carotid artery aneurysm & $4(1 \%)$ \\
\hline Anterior choroidal artery aneurysm & $6(1,5 \%)$ \\
\hline Pericallosal artery aneurysm & $5(1.5 \%)$ \\
\hline Ophthalmic artery aneurysm & $6(1.5 \%)$ \\
\hline Total & $384(100 \%)$ \\
\hline
\end{tabular}

After clinical assessment, each patient performed cerebral computed tomography (CT) scan and conventional cerebral angiography with digital subtraction. If treatment options, clipping or coiling, were considered equal, in MCA aneurysm surgery had priority.

The data of all our consecutive patients, surgically treated for MCA aneurysms, were searched to obtain patient characteristics, details of the aneurysm size and orientation, treatment details, complications and follow up. At admission, the clinical condition of all patients was classified according to the Hunt and Hess scale. Clinical outcome was graded according to the modified Rankin scale.

Only 3 patients with an unruptured MCA aneurysm (Hunt\&Hess 0) were included in this series. Most of the patients were diagnosed as a cause of haemorrhagic stroke, subarachnoid haemorrhage or intracerebral hematoma. Patients with a ruptured aneurysm of a good grade (Hunt\&Hess 1-3) were, as a rule, treated within 48-72 $\mathrm{h}$ after the diagnosis of the aneurysm. In a minority of symptomatic patients, the treatment of the ruptured aneurysm was postponed because of comorbidity, late referral or poor clinical condition of the patient (Hunt\&Hess 4-5). In these cases, acute hydrocephalus or clinical vasospasm, were treated before making the final decision about the timing of aneurysm clipping. In case of multiple aneurysms, treatment was at first selectively aimed at the ruptured aneurysm; additional unruptured aneurysms were not treated in the same session, unless in the same surgical field.

\section{RESULTS}

The patient characteristics are presented in Table 2.

TABLE 2 - Characteristics of patient with MCA aneurysms in our series

\begin{tabular}{|l|l|}
\hline Characteristic & No of patients (\%) \\
\hline Male & $42(36.2 \%)$ \\
\hline Female & $74(63.8 \%)$ \\
\hline \multicolumn{2}{|l|}{ Hunt \&Hess scale } \\
\hline Grade 0 & $5(4.2 \%)$ \\
\hline
\end{tabular}




\begin{tabular}{|l|l|}
\hline Grade 1 and 2 & $81(70 \%)$ \\
\hline Grade 3 & $20(17.3 \%)$ \\
\hline Grade 4 & $8(6,8 \%)$ \\
\hline Grade 5 & $2(1.7 \%)$ \\
\hline Modified Fischer Grading Scale & $5(4.3 \%)$ \\
\hline No SAH present & $62(53.5 \%)$ \\
\hline Focal or diffuse thin SAH & $42(36.2 \%)$ \\
\hline Focal or diffuse thick SAH & $7(6 \%)$ \\
\hline Intraventricular haemorrhage &
\end{tabular}

There were 116 patients with MCA aneurysms operated in our series. Most of the patients were women (63.8\%). At the time of surgery, $70 \%$ of the patients were in grade 1 or 2 on Hunt\&Hess scale.
The aneurysm characteristics are summarized in Table 3. Most MCA aneurysms were larger than 5 $\mathrm{mm}(70 \%)$.

TABLE 3 - Aneurysms characteristics

\begin{tabular}{|l|l|}
\hline Characteristics & No of patients (\%) \\
\hline Left MCA & $51(44 \%)$ \\
\hline Right MCA & $65(56 \%)$ \\
\hline Location & $109(94 \%)$ \\
\hline MCA bifurcation & $5(4.3 \%)$ \\
\hline M1 (pre-bifurcation segment) & $2(1.7 \%)$ \\
\hline M2/M3 (post-bifurcation) & \\
\hline Size & $37(31.9 \%)$ \\
\hline$\leq 5 \mathrm{~mm}$ & $67(57.75 \%)$ \\
\hline $5-10 \mathrm{~mm}$ & $12(10.35 \%)$ \\
\hline$\geq 10 \mathrm{~mm}$ &
\end{tabular}

Surgical clipping of an MCA aneurysm was performed following a subarachnoid haemorrhage in most of the patients, only in 3 cases the aneurysm was unruptured. The majority of the patients, 83 representing $71.5 \%$, was treated within $96 \mathrm{~h}$ following the haemorrhage. Five patients had postponed clipping of ruptured aneurysm, due to re-bleeding, important medical co-morbidities and acute hydrocephalus that needed external drainage. Seven patients harboured a coincidental non-ruptured posterior communicating artery aneurysm (3 cases) and anterior communicating artery aneurysm (4 cases), which were clipped in the same surgical procedure. Fourteen patients presented with significant hematoma which required the evacuation of the clot. Post-operative control angiography was performed in 32 patients (27.5\%), from which we reported a full occlusion of the aneurysm in 32 patients (93.75\%).

TABLE 4- Procedural and perioperative complication

\begin{tabular}{|c|c|c|}
\hline \multicolumn{2}{|c|}{ Complications } & No of cases \\
\hline \multicolumn{2}{|l|}{ Intraoperative rupture } & $18(15.5 \%)$ \\
\hline \multicolumn{2}{|c|}{ Re-ruptured before surgery (waiting) } & $1(0.85 \%)$ \\
\hline \multicolumn{2}{|l|}{ Post-operative rupture } & $1(0.85 \%)$ \\
\hline \multirow[t]{2}{*}{ Pre-operative vasospasm } & angiography & $14(12 \%)$ \\
\hline & clinic & $6(5 \%)$ \\
\hline \multirow[t]{2}{*}{ Post-operative vasospasm } & angiography & $15 / 32(46.85 \%)$ \\
\hline & clinic & $23(20 \%)$ \\
\hline \multicolumn{2}{|c|}{ Post-operative subdural hematoma } & $2(1.7 \%)$ \\
\hline \multicolumn{2}{|l|}{ Meningitis } & $3(2.5 \%)$ \\
\hline \multicolumn{2}{|l|}{ Hydrocephalus } & $8(7 \%)$ \\
\hline
\end{tabular}




\begin{tabular}{|l|l|}
\hline VP shunt (within 30 days from surgery) & $4(3.5 \%)$ \\
\hline Epilepsy & $2(1.7 \%)$ \\
\hline
\end{tabular}

Preoperative vasospasm was demonstrated on cerebral angiography in 14 patients (12\%) and clinically was manifested in 6 patients (5\%). As postoperative event, 23 patients, including the ones with preoperative neurological signs, presented clinical symptoms of vasospasm including insidious onset of a decreasing level of consciousness, affected speech and/or motor deficits. On control angiography, cerebral vasospasm was detected on near half of the patients (46.85\%).

Preoperative subarachnoid rebleeding, while waiting surgery, occurred in one patient. Postoperative rebleeding of a clipped MCA aneurysm occurred once, leading to a poor outcome.

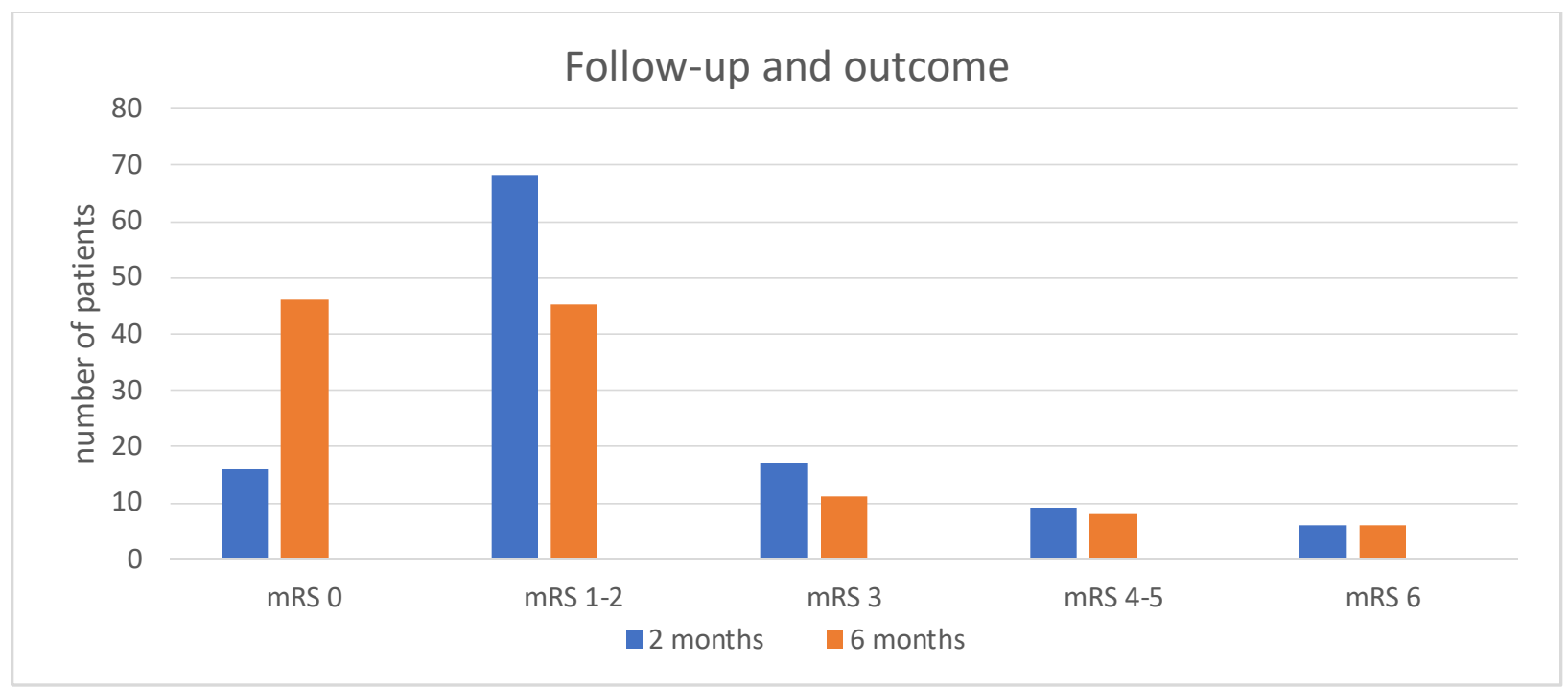

Outcome of the surgically treated MCA aneurysms after 2 months and after 6 months follow-up. Excellent and good=mRankin 0-2, fair= mRankin 3, poor=mRankin 4-5, death=mRankin 6

The follow-up period varied widely from 2 to 72 months (mean 30 months). Best results were obtained in patients who preoperatively were included in 1st and 2nd grade of Hunt \& Hess scale. Follow-up of the surgically treated symptomatic patients at 2 months was complete for all but 6 patients who died of neurologic or systemic causes. Perioperative mortality was $5.2 \%$ (6 patients), due to neurological (delayed cerebral ischemia-3 patients and meningitis-1 patient) or systemic causes (pulmonary embolism -2 patients). The mean followup was 30 months, obtained in $94.8 \%$ of the patients. The outcome was graded mRankin $0-2$ in $72.5 \%$ of the cases (84 patients) at the end of the first postoperative months, and $78.5 \%$ (91 patients) at six months follow-up. The most important improvement was recorded for patients graded mRankin 1-2 at the first month follow-up. All 3 patients with a surgically treated asymptomatic MCA aneurysm had an excellent outcome ( $\mathrm{mRS} 0$ ) at both follow-up, 1 months and respectively 6 months.
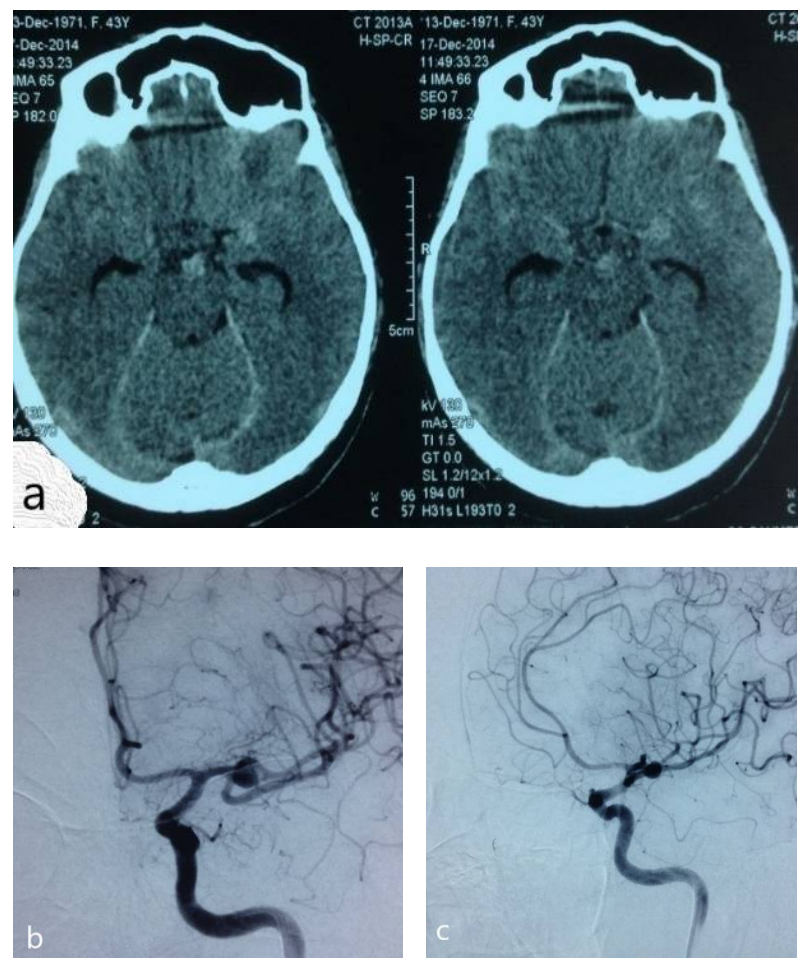

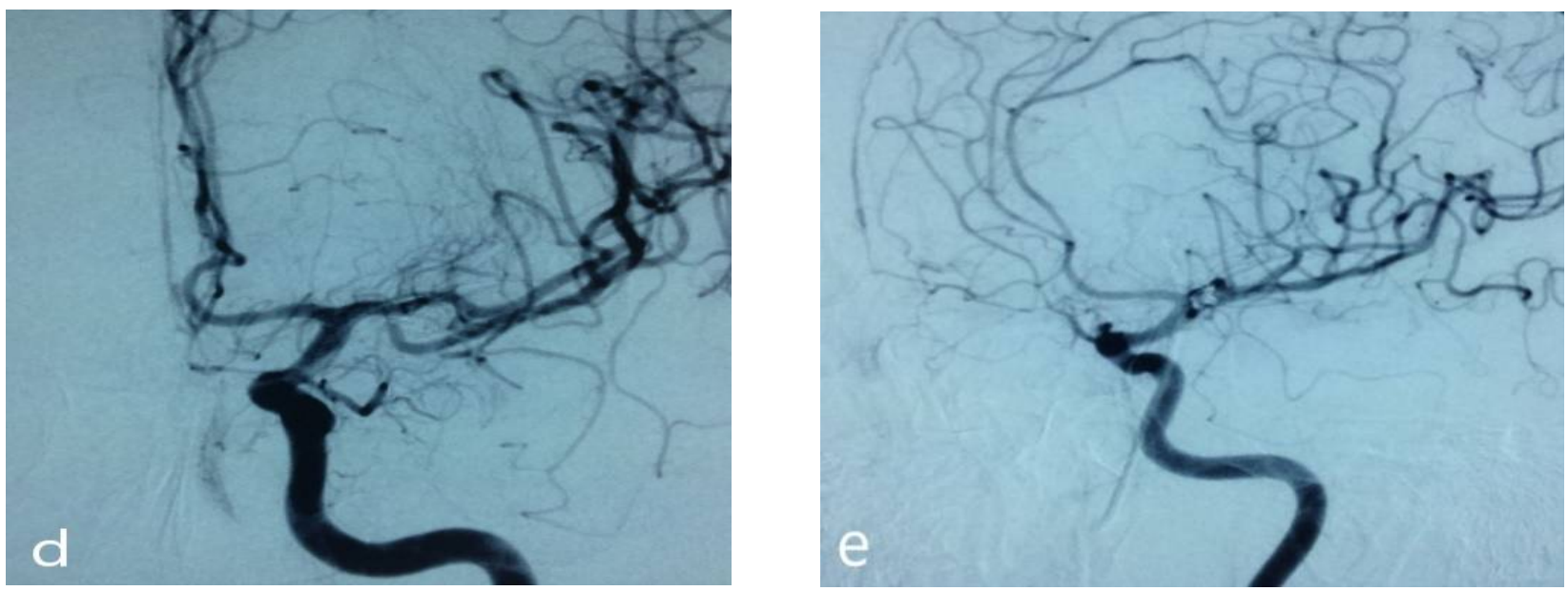

FIGURE LEGEND: (a) Preoperative native cerebral computed tomography (CT) showing subarachnoid haemorrhage, mainly in the left sylvian fissure; $(b, c)$ Preoperative four vessels cerebral angiography showed a $8 \mathrm{~mm}$ length left middle cerebral artery bifurcation aneurysm; (d,e) Postoperative control cerebral angiography showed the correct clipping of the aneurysm and the preservation of both M2 branches.

\section{DISCUSSIONS}

The middle cerebral artery (MCA) is the largest of the cerebral arteries. The diameter of the MCA at its origin is about $4 \mathrm{~mm}$ (range, 2.4-4.6 mm). The MCA starts as the larger and the more direct branch at the internal carotid artery bifurcation and courses laterally below the anterior perforated substance within the sylvian fissure, where it gives rise to the lateral lenticulostriate arteries and cortical branches and, then, divides into its main trunks $(23,28)$. The MCA is classically subdivided into four segments: the sphenoidal (M1) segment extending from the internal carotid artery bifurcation to the main MCA bifurcation where insular trunks (M2) begin and course over the insula until the peri-insular sulcus, where the opercular (M3) segments start and continue until the lateral surface of the brain in the sylvian fissure and, then, continue as cortical (M4) segments $(23,31)$.

The middle cerebral artery (MCA) harbors approximately $30 \%$ of all ruptured cerebral aneurysms and $36 \%$ of all unruptured cerebral aneurysms $(7,10)$. MCA aneurysms are classically divided into three groups: proximal middle cerebral artery aneurysms (M1 aneurysms), main middle cerebral artery bifurcation aneurysms (bifurcation aneurysms) or distal middle cerebral artery aneurysms (M3 or M4 aneurysms) $(7,15)$. Most of them are located at the MCA bifurcation and often project laterally in the plane of the M1 segment (11). Each location raises different surgical considerations, but the anatomic features of MCA aneurysms render them amenable to microsurgical clipping as the primary treatment of choice for most patients. In addition, MCA aneurysms are often broad necked and incorporate branches at the neck, which challenges endovascular coiling more than surgical clipping $(15,21)$.

Around $40 \%$ of patients with MCA aneurysms have multiple aneurysms, in contradistinction to approximately $20 \%$ of those with aneurysms in other locations (25). Moreover, mirror aneurysms can be seen in $13 \%$ of patients with MCA aneurysms $(25,29)$.

Microsurgical clipping of MCA aneurysms is still the preferred treatment modality in most centers due to the relatively straightforward surgical approach to these relatively superficial aneurysms $(2,11)$. Surgery provides effective and durable exclusion of MCA aneurysms, and, also, allows the reduction of intracranial pressure through evacuation of related intracerebral hematoma. The different locations of MCA aneurysms pose distinct challenges to the neurosurgeon and require specific surgical strategies.

Proximal MCA aneurysms (M1 aneurysms) are especially challenging lesions because of their intimate relation to lateral lenticulostriate artery. These perforators arteries may arise from the M1 segment or from the aneurysm neck itself. These branches are quite easily damaged during dissection, included with the aneurysm during clipping or compressed by the clip with subsequent thrombosis $(2,12)$. Lateral lenticulostriate arteries irrigate eloquent areas of the brain and, thus, 
damage to them could result in a poor clinical outcome.

The M1 bifurcation is the most common location for aneurysms in the MCA. In a large series, $60-83 \%$ of middle cerebral artery aneurysms are located at the bifurcation $(24,31)$. The bifurcation of the MCA typically lies medial to the junction of the horizontal and anterior portions of the Sylvian fissure near the anterior edge of the island of Reil or limen insulae. Clipping of MCA bifurcation aneurysm must be precise with careful attention paid to the origins of the $\mathrm{M} 2$ branches. After $\mathrm{M} 1$ is exposed the dissection proceeds distally along the anterior and inferior aspects of M1 to reach the aneurysm neck at the MCA bifurcation (9). Anteriorly pointing aneurysms allow M1 exposure along their posterior pole, and, posteriorly pointing aneurysms allow M1 exposure along their anterior pole. Some mobilization of the M2 trunks may be necessary for creating enough space to place a temporary clip on $\mathrm{M} 1(8,16)$.

Temporary clipping is very important, because it softens the aneurysm sac during difficult and risky dissection maneuvers and is particularly helpful for isolating branching and perforating arteries adherent to the dome. Anterior temporal artery and both $\mathrm{M} 2$ branches should be completely dissected free, before clip application. The aneurysm neck should usually be clipped along the plane of the M2 branches and perpendicular to the M1 (14). After clip application, the tips of the blades should be inspected to ensure the safety of all branching and perforating vessels. Care must be taken not to kink the frontal or temporal M2s. "Perfect" clip application is dangerous and often leads to stenosis of the M2 outlets $(14,16)$.

Multilobed aneurysms often require more than one clip and more complex clip reconstruction. They often also have calcified or atheromatous walls, all this requiring higher closing pressure or grater occlusion surfaces for full obliteration. In these situations, tandem- clipping techniques applying fenestrated clips with higher closing pressure to the distal neck supplemented by proximal neck occlusion with non-fenestrated clips are useful $(6,14)$. Sometimes, in large ruptured MCA aneurysms, temporary clipping of the dome will provide sufficient control of the bleeding site to facilitate final dissection of the neck $(6,17)$.

The main challenge during surgery for distal MCA aneurysm is to localize it, particularly when they are small and distal to the M2-M3 junction or when the Sylvian fissure is filled with subarachnoid hemorrhage or intracerebral hematoma (7). Localization of distal MCA aneurysms requires more experience and careful study of the preoperative angiography. The distance from the MCA genu, the location in relation to the associated ICH if present, the depth of the aneurysm from the surface of the brain are some of the data that can be obtained from CTA and which can help during surgery $(2,7)$. Neuronavigation, intraoperative DSA or intraoperative ultrasound might also be considered.

Giant and fusiform aneurysms of the bifurcation may require bypasses techniques. When performing the craniotomy for a large MCA aneurysm, it is important to preserve at least one branch of the superficial temporal artery (STA) in case an unanticipated STA-MCA bypass is needed. High-flow extracranial-intracranial bypasses using saphenous vein or radial artery grafts may needed to be considered for fusiform aneurysms involving more than one branch (16).

The implementation of adjunctive tools including somatosensory evoked potential (SSEP) monitoring, indocyanine green (ICG) angiography or intraoperative digital subtraction angiography (DSA) improve surgical outcomes by providing critical information regarding optimal clip placement (5).

Efficacy of endovascular approach was evaluated in multicenter randomized control trials (RCT) as the International Subarachnoid Aneurysm Trial (ISAT) started in 2002 or the Barrow Ruptured Aneurysm Trial (BRAT) started in 2003 (18,19). In both trials, the early results at 1-year follow-up suggested superiority of coiling compared to clipping. But, longterm follow-up outcomes in both studies, evaluated at more than 3 years, demonstrated an attenuation of the benefit gain achieved by endovascular treatment to the point where no significant difference of neurological outcome was observed between the two treatment modalities $(18,27)$. In the endovascular group, at long term follow-up, higher re-bleeding risk, lower obliteration rate and higher retreatment rate were noticed. But there were no specific randomized control trials to compare safety and efficacy of MCA aneurysm treatment between the two modalities. Regli et al. (22) described the first series of comparison between endovascular and surgical treatment in a single cohort; the surgical results were excellent with only $3 \%$ morbidity, 
compared with a failure rate of $85 \%$ in coiling, with only two patients successfully treated by coiling with a "first coil" policy.

A most recent comparison study (2014) was conducted by Diaz and co-workers (9) but with the selection criteria bearing a moderate disadvantage towards surgery, where for all ruptured MCA aneurysm a "coil first" strategy was implemented and for unruptured MCA aneurysms only large ones were recommended to undergo clipping. The authors reported comparable results in poor outcome for coiling (10\%) and clipping (5.9\%) with a slight advantage toward surgery. They also observed a $14 \%$ recanalization of the aneurysm in endovascular group in comparison to none in the surgery group in a 9-months follow-up period (9). All these results were supported by evidence from systematic reviews and meta-analysis of the current literature that showed slight to moderate advantage of surgery over endovascular embolization in treatment of MCA aneurysms $(1,30)$.

For ruptured MCA aneurysms, the outcome after endovascular treatment is reported to be good in $48-100 \%$ of cases and poor in up to $52 \%$ of cases with a mortality rate of up to $14 \%(3,4)$. The outcome after the surgical treatment of ruptured MCA aneurysms is recorded to be good in $55-95 \%$ of cases and poor in 5-45\% with a mortality rate of up to $13 \%(20,26,27)$. For unruptured MCA aneurysms, the outcome after endovascular treatment is reported to be good in 93-99\% of cases and poor in up to $5 \%$ of cases with a mortality rate of up to $3 \%$ $(3,22)$. The outcome of surgical treatment is recorded to be good in $88-100 \%$ of cases and poor in $4-12 \%$ of cases with a mortality rate of up to $2 \%(2,8,26)$.

\section{Conclusions}

A good anatomic understanding of MCA branching patterns and sylvian fissure compartments, and experience with standard management strategies are required to effectively treat these, often, complex aneurysms. All attempts to treat MCA aneurysms endovascularly, despite ample progress in endovascular techniques and devices has been made, are unjustified in a situation where an excellent surgical solution is at hand. For experienced neurovascular team, MCA aneurysms currently make microsurgical treatment the preferred treatment modality for most MCA aneurysms.

\section{REFERENCES}

1. Blackburn $S L$, Abdelazim $A M$, Cutler $A B$, Brookins $K T$, Fargen $\mathrm{KM}$, Hoh BL, et al. Endovascular and surgical treatment of unruptured MCA aneurysms: meta-analysis and review of the literature. Stroke Res Treat. 2014;34847.

2. Bohnstedt, B.N., H.S. Nguyen, C.G. Kulwin, M.M. Shoja, G.M. Helbig, T.J. Leipzig, T.D. Payner, and A.A. Cohen-Gadol, Outcomes for clip ligation and hematoma evacuation associated with 102 patients with ruptured middle cerebral artery aneurysms. World Neurosurg, 2013. 80(3-4): p. 33541.

3. Bracard, S., A. Abdel-Kerim, L. Thuillier, O. Klein, R. Anxionnat, S. Finitsis, A. Lebedinsky, C.M. de Freitas, N. Pinheiro, G.C. de Andrade, and L. Picard, Endovascular coil occlusion of 152 middle cerebral artery aneurysms: initial and midterm angiographic and clinical results. J Neurosurg, 2010. 112(4): p. 703-8.

4. Brinjikji, W., G. Lanzino, H.J. Cloft, A. Rabinstein, and D.F. Kallmes, Endovascular treatment of middle cerebral artery aneurysms: a systematic review and single-center series. Neurosurgery, 2011. 68(2): p. 397-402; discussion 402.

5. Caplan JM, Sankey E, Yang W, Radvany MG, Colby GP, Coon $A L$, et al. Impact of indocyanine greenvideoangiography on rate of clip adjustments following intraoperative angiography. Neurosurgery. 2014;75(4):437-434.

6. Chyatte D, Porterfield R. Nuances of middle cerebral artery aneurysm microsurgery. Neurosurgery. 2001;48:339-346.

7. Dashti, R., J. Hernesniemi, M. Niemela, J. Rinne, M. Lehecka, H. Shen, H. Lehto, B.S. Albayrak, A. Ronkainen, T. Koivisto, and J.E. Jaaskelainen, Microneurosurgical management of distal middle cerebral artery aneurysms. Surg Neurol, 2007. 67(6): p. 553-63

8. Dashti R, Hernesniemi J, Niemela M, Rinne J, Porras M, Lehecka M, Shen H, Albayrak BS, Lehto H, Koroknay-Pál P, de Oliveira RS, Perra G, Ronkainen A, Koivisto T, Jääskeläinen JE. Microneurosurgical management of middle cerebral artery bifurcation aneurysms. Surg Neurol. 2007; 67:441-456.

9. Diaz OM, Ranger-Castila L, Barber S, Mayo RC, Klucznick R, Zhang YJ. Middle cerebral artery aneurysms: a single-center series comparing endovascular and surgical treatment. World Neurosurg. 2014;81(2):322-329.

10. Doerfler, A., I. Wanke, S.L. Goericke, H. Wiedemayer, T. Engelhorn, E.R. Gizewski, D. Stolke, and M. Forsting, Endovascular treatment of middle cerebral artery aneurysms with electrolytically detachable coils. AJNR Am J Neuroradiol, 2006. 27(3): p. 513-20.

11. Elsharkawy, A., M. Niemela, M. Lehecka, H. Lehto, B.R. Jahromi, F. Goehre, R. Kivisaari, and J. Hernesniemi, Focused opening of the sylvian fissure for microsurgical management of MCA aneurysms. Acta Neurochir (Wien), 2014. 156(1): p. 17-25.

12. Guresir, E., P. Schuss, J. Berkefeld, H. Vatter, and V. Seifert, Treatment results for complex middle cerebral artery aneurysms. A prospective single-center series. Acta Neurochir (Wien), 2011. 153(6): p. 1247-52. 
13. Heros R. Aneurysms in the middle cerebral artery. In Simon L, Thomas DGT, Clarke K (eds): Rob and Smith's Operative Surgery: Neurosurgery. New York: Chapman \& Hall, 1994, pp 171-179.

14. Heros, R.C. and M.J. Fritsch. Surgical management of middle cerebral artery aneurysms. Neurosurgery, 2001. 48(4): p. 780-5; discussion 785-6.

15. Hosoda, K., S. Fujita, T. Kawaguchi, Y. Shose, and S. Hamano, Saccular aneurysms of the proximal (M1) segment of the middle cerebral artery. Neurosurgery, 1995. 36(3): p. 441-6

16. Lawton MT. Middle cerebral artery aneurysms, in: Seven Aneurysms: Tenets and Techniques for Clipping. New York: Thieme Medical Publishers, 2011.

17. Madhugiri VS, Ambekar S, Pandey P, et al. The pterional and suprabrow approaches for aneurysm surgery: a systematic review of intraoperative rupture rates in 9488 aneurysms. World Neurosurg. 2013;80:836-844.

18. McDougall CG, Spetzler RF, Zabramski JM, Partovi S, Hills NK, Nakaji $P$, et al. The Barrow ruptured aneurysm trial. J Neurosurg 2012;116(1):135-44.

19. Molyneux A, Kerr R, Stratton I, Sandercock P, Clarke M, Shrimpton J, et al. International Subarachnoid Aneurysm Trial (ISAT) of neurological clipping versus endovascular coiling in 2143 patients with ruptured intracranial aneurysms: a randomized trial. Lancet 2002; 360 (9342):1267-74.

20. Morgan, M.K., W. Mahattanakul, A. Davidson, and J. Reid, Outcome for middle cerebral artery aneurysm surgery. Neurosurgery, 2010. 67(3): p. 755-61; discussion 761.

21. Quadros, R.S., S. Gallas, R. Noudel, P. Rousseaux, and L. Pierot, Endovascular treatment of middle cerebral artery aneurysms as first option: a single center experience of 92 aneurysms. AJNR Am J Neuroradiol, 2007. 28(8): p. 1567-72.

22. Regli L, Uske A, de Tribolet N. Endovascular coil placement compared with surgical clipping for the treatment of unruptured middle cerebral artery aneurysms: a consecutive series. J Neurosurg 1999;90 (6):1025-30.
23. Ring, B.A., Middle cerebral artery: anatomical and radiographic study. Acta Radiologica, 1962. 57: p. 289-300.

24. Rinne J, Hernesniemi J, Niskanen M, et al. Analysis of 561 patients with middle cerebral artery aneurysms: Anatomic and clinical features as correlated to management outcome. Neurosurgery 38:2-11, 1996.

25. Rinne, J., J. Hernesniemi, M. Puranen, and T. Saari. Multiple intracranial aneurysms in a defined population: prospective angiographic and clinical study. Neurosurgery, 1994. 35(5): p. 803-8.

26. Rodriguez-Hernandez, A., M.E. Sughrue, S. Akhavan, J. Habdank-Kolaczkowski, and M.T. Lawton, Current management of middle cerebral artery aneurysms: surgical results with a "clip first" policy. Neurosurgery, 2013. 72(3): p. 415-27.

27. Spetzler RF, McDougall CG, Albuquerque FC, ZabramskiJM, Hills NK, Partovi S, et al. The Barrow ruptured aneurysm trial: 3-year results. J Neurosurg. 2013:19(1):146-57.

28. Ture, U., M.G. Yasargil, O. Al-Mefty, and D.C. Yasargil. Arteries of the insula.J Neurosurg, 2000. 92(4): p. 676-87.

29. Ulm, A.J., G.L. Fautheree, N. Tanriover, A. Russo, E. Albanese, A.L. Rhoton, Jr., R.A. Mericle, and S.B. Lewis, Microsurgical and angiographic anatomy of middle cerebral artery aneurysms: prevalence and significance of early branch aneurysms. Neurosurgery, 2008. 62(5 Suppl 2): p. ONS344-52; discussion ONS352-3.

30. Zaidat OO, Castonguay AC, Teleb MS, Asif K, Gheith A, Southwood $C$, et al. Middle cerebral artery aneurysm endovascular and surgical therapies: comprehensive literature review and local experience. Neurosurg Clin N Am. 2014;25(3):455-69.

31. Yasargil MG. Middle cerebral artery aneurysms. In Yasargil MG (ed): Microneurosurgery, vol 2. Stuttgart: Thieme Verlag, 1984, pp 124-164. 